\title{
Improving the Performance of Agriculture Irrigation System using Arduino
}

\author{
Ramkumar Adhi, Rajesh Krishnasamy, M. Nitish, S. Yashwant Kumar, D. Edwin Deva \\ Asirvatham, Booma Jeyabalan
}

\begin{abstract}
Irrigation process is nothing but a cultivation of agricultural crops during the inadequate rainfall. And also it is used to maintain the landscapes. Now a days, irrigation process to the crops are very difficult and the farmers facing lot of problems to get the good quality of crops because of providing the sufficient quantity of water with the precious time feed to the crops is most difficult task. This problem can be overcome by automatic irrigation system. In recent years, lot of researchers focusing towards the automatic irrigation for helping to reduce the burden of farmers and also they are focusing about to properly cultivate the crops with the proper time period. In this proposed work, by using the arduino uno, the automatic irrigation process is done in effectively. With the additional accessories and components along with the arduino such as moisture sensor, solenoid value, relay modules and adapter provides the effective irrigation system. This proposed system is focusing to feed the necessary water to the crops based on its natural character automatically by the arduino code of the system. Also it protects the farmers against the injury causes due to harmful insects in the agriculture land when working in night.

Keywords: Arduino uno, Moisture sensor, relay module, solenoid valve.
\end{abstract}

\section{INTRODUCTION}

$\mathrm{T}$ oday's world, whatever technology which are used in domestic, industries and agriculture systems, the automation technology is wide spreading for improving the performance of the system and reduce the manpower. In our India, $40 \%$ of

Revised Manuscript Received on December 05, 2019.

* Correspondence Author

A. Ramkumar*, Department of Electrical and Electronics Engineering, Kalasalingam Academy of Research and Education, Krishnankoil, TamilNadu, India. Email: a.ramkumar@klu.ac.in

K. Rajesh, Department of Electrical and Electronics Engineering, Kalasalingam Academy of Research and Education, Krishnankoil, TamilNadu, India. Email: k.rajesh@klu.ac.in

Mr.M. Nitish, UG Student, Electrical and Electronics Engineering, Kalasalingam Academy of Research and Education Anand Nagar, Krishnannkoil, Virudhunagar, India, amnitish10@gmail.com

Mr. S. Yashwant Kumar, UG Student, Electrical and Electronics Engineering, Kalasalingam Academy of Research and Education. Anand Nagar, Krishnannkoil, Virudhunagar, India, yeshwantyesh06@gmail.com

Mr. D. Edwin Deva Asirvatham, UG Student, Electrical and Electronics Engineering, Kalasalingam Academy of Research and Education. Anand Nagar, Krishnannkoil, Virudhunagar, India edwindeva@gmail.com

Dr.Pooma Jeyabalan, Assis.Prof, Electrical and Electronics Engineering, PSNA College of Engineering, Dindugal, Madurai,, India, boomadhyana2009@gmail.com people are mainly depending upon the agriculture and it is one of the most important mankind in our India [1]. farmers doesn't have the sufficient knowledge about their lands that it the fertility, cannot able to choose the right seeds for their agriculture lands [2].

Without the water, we never imagine the process of agriculture system. So, effective utilization of water for the irrigation is most important task in the agriculture system. Also some of the Such problems can be avoided by effective automatic agriculture irrigation system. This automatic system are very much essential now a days to the farmers for knowing their soil natural property as well as which type of seeds are much suitable for their land [3]. Also feeding the water to the crops with the sufficient quantity at precious time interval can be done. This system is widely suitable to the farmers those who are working in night hours because of avoiding injury by harmful insects and provides the safety / security to them.

In this automation system, the amount of moisture content in the land can be sensed by moisture sensor. This is very helpful to detect the wet / dry conditions of land and analyze to make a strategy for the required quantum of water flow to the particular area of the land [4-6]. In particular, this project proposal is essential to the less availability of water in rural areas for saving the water required to the agriculture land and also provide safety and security to the farmers [7-10].

This paper is organized by five chapters such as Chapter-I: Introduction deals the need of automation in agriculture process. Chapter-II deals the literature survey about the proposal. Chapter-III discusses the proposed methodology of the automation system. Chapter-IV deals the complete block diagram for the proposed methodology and Chapter-V discusses the results about the project.

\section{LITERATURE SURVEY}

Pavithra, et.al., discussed the GSM based Automatic Irrigation Control System for efficient use of resources by using mobile phones. By using GSM techniques, it gives the convenient feature to the farmers for their work and gets notified. Due to this process are well aware of the process of the system and are able to do their work without getting any problem. And are useful for the user to get notified even if he is out of the village for a short time he can monitor the work happening in the field and is able to stop and start the process whenever needed.

Venkata Naga Rohit Gunturi, "Micro Controller Based Automatic Plant Irrigation" discussed the entire system is controlled using microcontroller and it give the 
interrupt signal to the motor. Temperature and humidity sensors are used to sense the humidity and temperature of the soil.

DC Slaughter et.al., deals the development and application of computer hardware, software, electronic instrumentation and control systems for solving problems in agriculture and related industries.

Archana et.al., discussed the humidity and soil moisture of the root of the plant, by using moisture sensors. Microcontroller takes the readings of the root zone by sensors in the agriculture area. Based on the reading, the chances of error in the system is reduced thus the automation is done effectively.

Gunturi discussed the project in conservation of excess of water used in the field and also proposed the many techniques for controlling the wastage by using 3.5 microprocessor.

VR balaji et.al., published a project and it is not depending on electricity and power supply feed to the project using solar PV system. Also soil moisture sensors are used to find values of microcontroller which is used to control the motor.

Karan kansara developed automatic irrigation system using microcontroller. With the help of GSM module, the signal can generate, transmit and decode from cellular network and the work is easy and done in effective manner.

Joaquin Gutierrez published a project for the irrigation processing using photovoltaic panel. This project is more suitable for the summer season for helping to save the usage of water. Solar based plant irrigation in which the water is drawn by a submersible pump and sprinklers the water in the plants.

BR Shiraz Pasha, et.al., discussed to use the ATMEGA3 Microcontroller which is giving the interrupt signal to the motor and also provides the information about automatic irrigation.

$\mathrm{N}$ Wang proposed the computers and electronics in agriculture provides an international view in development of hardware, software and control system. This proposed method is based on automatic irrigation system by using advanced technology and hardware.

By using the above mentioned literature survey, the following proposed system is planned to improve the performance of automatic agriculture irrigation system. In this proposed system, arduino uno is used due to the cost factor and also the system can be easily controlled by the farmer at different locations.

\section{PROPOSED METHODOLOGY}

In this proposed system, arduino uno is the central hub of the automation process. Whatever the monitoring and control processes for the agriculture irrigation can be done by and through only arduino uno. Relay module, moisture sensors and solenoid valves are the other important components for the agriculture automation system. The process of work also includes the light emitting diode for monitoring the work done in the field. The total area of the land is separated into number of phases and those phases are monitored by separate moisture sensors.
At the entry and exit stages, the moisture sensors are attached for sensing the wet / dry conditions of land. If the land is dry, the water is fed to the respective land area by one end of moisture sensor at the respective phase. The other end of the moisture sensor senses the water flows through the field as moisture is indicated the flow of water is stopped. The same process is started to the next dry area for the irrigation. Such a process is done to several phases of the land and it avoids the water for overflowing.

In this proposed system, five relay modules are connected with the arduino uno for indicating which area is irrigated and it shuts off the respective light based on the moisture is detected by the respective sensor. The four solenoid valves which are connected with the arduino are controlling the water flows through the valve. If the digital signal through the arduino is indicated as " 0 ", the condition becomes low and if the system indicated as " 1 ", the condition becomes high. Arduino is coded to turn "OFF" the motor, if the condition is high, and if the condition is low, the motor is made to turn $\mathrm{ON}$.

By this way, the system is working efficiently and fed the water only to the areas which is needed water and it is switched off if the water is not necessary to the particular phase of the land. Hence, it avoids the water wastage and also saves a huge quantum of water for avoiding over watering.

\section{BLOCK DIAGRAM FOR THE PROPOSED METHODOLOGY}

The major components of the proposed work are arduino uno (ATmega328p), moisture sensor, relay module and solenoid and motor for pumping the water. The detailed descriptions about those components are:

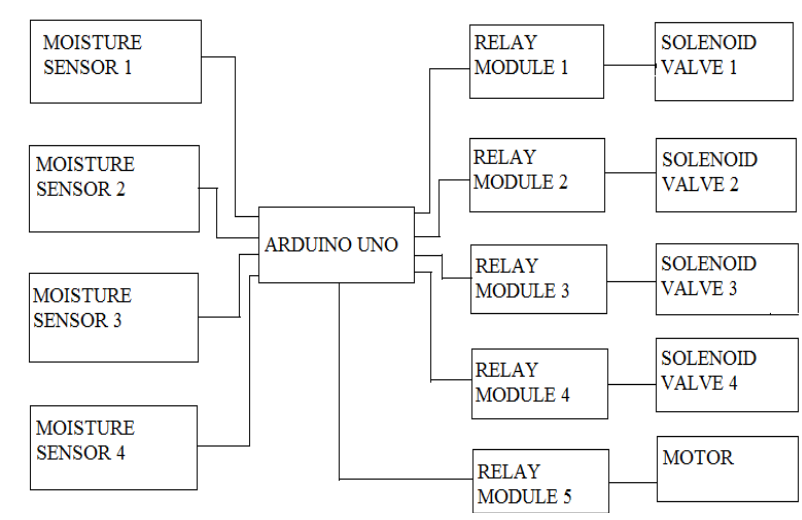

Fig. 1 Block diagram for automation irrigation system

Arduino Uno: It is a microcontroller board based on the ATmega328P. It is having 14 digital input/output, 6 analog inputs, $16 \mathrm{MHz}$ quartz crystal with USB connection. The power supply is provided by AC to DC adapter. This arduino uno is connected with a computer through USB cable. 


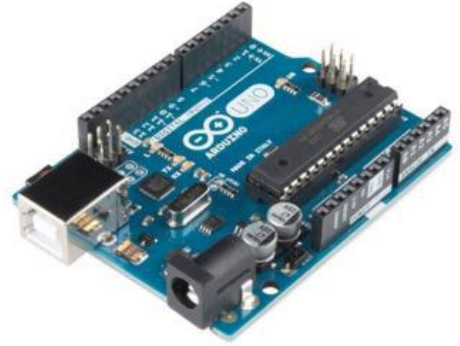

Fig. 2 Arduino Uno

"Uno" is the Italian word and it is marked to release the Arduino Software (IDE) 1.0. With the sets of digital and analog input / output pins, that is the possibility to interface the expansion of boards and circuits.

Moisture Sensor: Volumetric water content of the soil is measured by moisture sensors. Measurement of volumetric water content is used to indirectly measure the soil resistance, dielectric constants and property of soil.

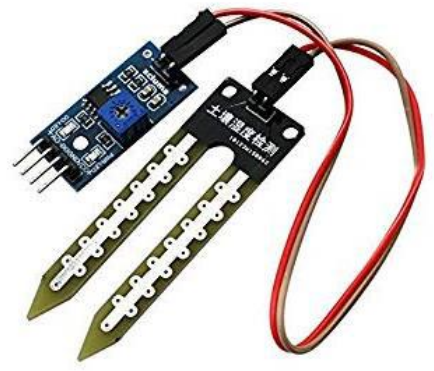

Fig. 3. Moisture Sensor

The moisture sensor is having two probes and used to measure the moisture value of the soil based on the resistance value of it. If more water available in the soil, it contacts more electricity due to less resistance of the soil. If less water, it conducts less electricity of more resistivity of soil.

Relay Module: In this proposed system, the single-channel simple relay module is used. It is having three terminals such as normally open, normally closed and common terminals. At "IN" pin, the low signal is applied for switch on the relay. This module doesn't have any holes for mounting.

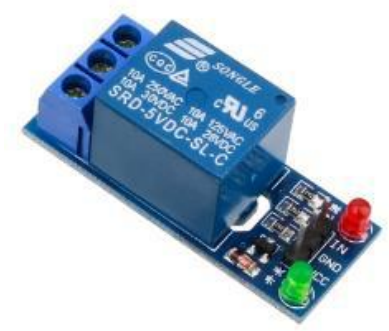

Fig. 4. Relay Module

It is a separate hardware device used in the automatic agriculture system. It can be controlled by remote control device through the network or the internet. Based on the commands received from arduino uno, the device can be powered on and off remotely through the wide area network.

Solenoid Valve: It is a electro-mechanical device. Magnitude of current which is flowing through the solenoid induces the magnetic field and it regulates the opening of valve.

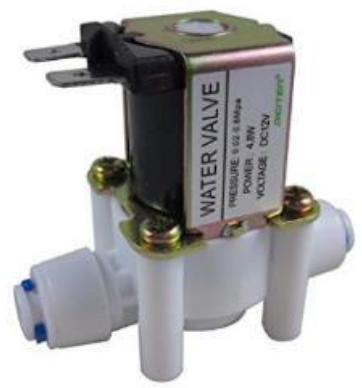

Fig. 5. Solenoid Valve

It is normally used as a control element for controlling the flow of fluids based on the electric current - magnetic field mechanism. It is highly reliable fast acting and safe switches for agriculture irrigation system.

\section{RESULTS AND DISCUSSION}

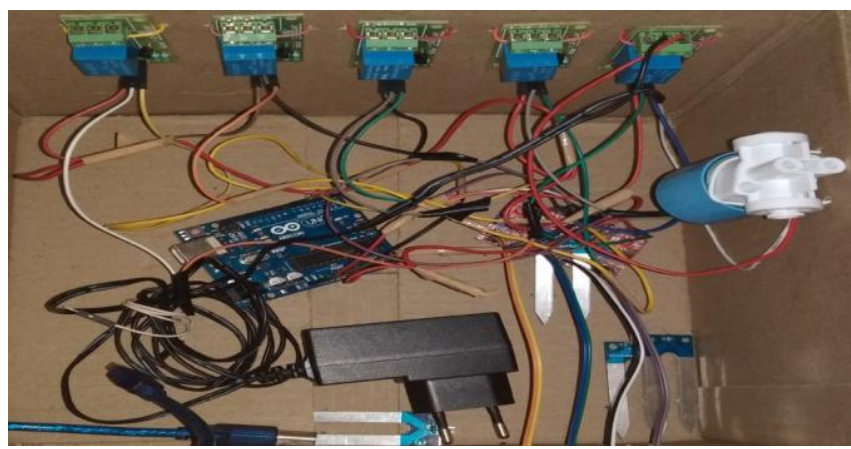

Fig. 6 Hardware Setup of Automation Irrigation System

Figure 6 shows the hardware arrangement of automation irrigation system using arduino uno. The moisture sensors are used to sense the moisture content of the soil by sending the current through the soil. If the soil is in dry condition, the resistive value of the soil is more. Otherwise the resistance is low at more moisture content of the soil.

Based on the resistive value of the soil, the sensor can sense and send the signal to the arduino uno for the availability of water in the area of agriculture land. Depends upon the requirement of water, the arduino uno gives the commands in the analog and digital formats to the respective relay module and its contacts are closed. If it is closed, the supply is given to the corresponding solenoid coil and the valve is opening depends upon the magnitude of magnetic field.

By this way, the amount of water flow to the agriculture land can be regulated and avoids the water wastage. In this hardware setup, $12 \mathrm{~V} \mathrm{DC}$ motor is used for pumping the water to the land. The IDE software is used in arduino uno because of uploading the programme to arduino is very easy by using this software. The threshold values are set depends upon the DC motor supplies the water to the soil. 


\section{CONCLUSION}

The main objective of this automatic irrigation system is to make the process to save the water with precious time. The hardware of the irrigation system properly worked in various soils. Based on its performance, this system is effectively suitable for the irrigation compare with the natural irrigation process for the less amount of manpower and time. Also farmer can operate this unit with the long distance. One of the major achievements of the proposal is to reduce the quantum of water used and only required amount of water is supplied to the crop at the right time. So the growth of crop is better than the natural irrigation system. In future work, the temperature sensors will be included with this project; it can extend the large agriculture plant also.

\section{APPENDIX}

Arduino Uno (ATmega328P) specifications:
\begin{tabular}{|l|l|}
\hline Recommended Input Voltage & $7-12 \mathrm{~V}$ \\
\hline Input Voltage Limits & $6-20 \mathrm{~V}$ \\
\hline Analog Input Pins & 6 (A0- A5) \\
\hline Digital I/O Pins & 14 \\
\hline
\end{tabular}

Moisture Sensor specifications:

\begin{tabular}{|l|l|}
\hline Working Voltage & $5 \mathrm{~V}$ \\
\hline Working Current & $<20 \mathrm{~mA}$ \\
\hline Interface type & Analog \\
\hline Working Temperature & $10^{\circ} \mathrm{C} \sim 30^{\circ} \mathrm{C}$ \\
\hline
\end{tabular}

Relay Module specifications:

\begin{tabular}{|l|l|}
\hline Supply Voltage & 3.75 to $6 \mathrm{~V}$ \\
\hline Current with De-energized & $2 \mathrm{~mA}$ \\
\hline Current with Relay energized & 70 to $72 \mathrm{~mA}$ \\
\hline Input Control Signal & Active Low \\
\hline Current Control Signal-Input & 1.5 to $1.9 \mathrm{~mA}$ \\
\hline Contact Voltage (Maximum) & 250 VAC or 30 VDC \\
\hline Contact Current (Maximum) & $10 \mathrm{~A}$ \\
\hline
\end{tabular}

Solenoid valve specifications:

\begin{tabular}{|l|l|}
\hline Supply Voltage & $12 \mathrm{~V} \mathrm{DC}$ \\
\hline Size & $1 / 4^{\prime \prime}$ \\
\hline Working pressure & $0.02-0.8 \mathrm{Mpa}$ \\
\hline Highest Working temperature & $60^{\circ} \mathrm{C}$ \\
\hline Rated power & $4.8 \mathrm{~W}$ \\
\hline
\end{tabular}

\section{REFERENCES}

1. Pavithra D. S ., SRinath M S., "GSM based Automatic Irrigation CONTROL System for EFFICIENT USE OF Resources AND CROP PLANNING BY USING AN ANDROID MOBILE", IOSR JOURNAL OF MECHANICAL AND CIVIL ENGINEERING, E-ISSN: 2278-1684,P-ISSN: 2320-334X, VOLUME 11, IsSUE 4 VER. I (JUL- AUG. 2014), PP 49-55.

2. Venkata Naga Rohit Gunturi, "Micro Controller Based Automatic Plant Irrigation System", International Journal of Advancements in Research \& Technology, Volume 2, Issue4, April-2013.
3. HA Archana, N. Asoka Raja, R Mahesh, R Kalpana, "Effect of Low Cost Drip Tape Irrigation System on Yield and Economics of Sweet Corn", Bangladesh Agron. J. 2016, 19(2): 71-77.

4. Karan Kansara, Vishal Zaveri, Shreyans Shah, Sandip Delwadkar, Kaushal Jani, "Sensor based Automated Irrigation System with IOT: A Technical Review", (IJCSIT) International Journal of Computer Science and Information Technologies, Vol. 6 (6) , 2015, 5331-5333.

5. Joaquin Gutierrez, Juan Francisco Villa Medina, Alejandra Nieto-Garibay, Miguel Angel Porta-Gándara, "Automated Irrigation System Using a Wireless Sensor Network and GPRS Module", IEEE Transactions on Instrumentation and Measurement 63(1):166-176 - January 2014, DOI: 10.1109/TIM.2013.2276487

6. P.Sindhura, P.Swathi, S.Ejas Basha, K.AnilKumar, "Agriculture Field Motor Control System Based on IOT", International Journal for Research in Applied Science \& Engineering Technology (IJRASET), Volume 5 Issue III, March 2017

7. Rajendranath Udathu, V. Berlin Hency, "Implementation of an automated irrigation system: Smart irrigation system", International Journal of Applied Engineering Research 10(20):16261-16265 · January 2015.

8. Zijing Chen, Yingyan Han, Kang Ning, Chen Luo, Wei Sheng, Shenglin Wang, Shuangxi Fan, Yanfang Wang, Qian Wang, "Assessing the performance of different irrigation systems on lettuce (Lactuca sativa L.) in the greenhouse", PLoS ONE 14(2): e0209329. https://doi.org/10.1371/journal.pone.0209329

9. Xiufang Zhu, Yizhan Li, Muyi Li, Yaozhong Pan, and Peijun Shi, "Agricultural irrigation in China", Journal of Soil and Water Conservation, NOV/DEC 2013-VOL. 68, NO. 6.

10. Mahir Dursun* and Semih Ozden, "A wireless application of drip irrigation automation supported by soil moisture sensors", Scientific Research and Essays Vol. 6(7), pp. 1573-1582, 4 April, 2011

\section{AUTHORS PROFILE}

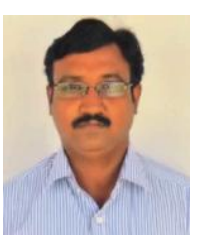

A. Ramkumar received the Ph.D degree from Kalasalingam Academy of Research andEducation in the year of 2014. He received the M.E (Power Systems) degree from Faculty of Engineering and Technology, Annamalai University, Chidambaram, Tamil Nadu, India, in2002 and received the B.E (Electrical and Electronics Engineering) from Thiagarajar Collegeof Engineering, M.K. University, Madurai, Tamil Nadu, India in the year of 1997. He hasbeen working as a Associate Professor in the Department of Electrical and ElectronicsEngineering, Kalasalingam Academy of Research and Education, Srivilliputhur, Tamil Nadu,since 2003. He is having more than 19 years' experience in the field of teaching. His researchinterests include Renewable Energy, Power System Planning, Power System Analysis, HighVoltage DC transmission Systems, Reactive Power Compensation, Flexible ACtransmissions Systems, Electrical Machines and Power System Automation. He is a Lifemember of ISTE and Member of IE(I).

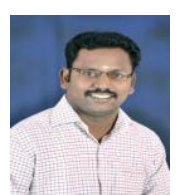

K. Rajesh was born in Rajapalayam, Tamil Nadu, India, in May 1987. He received his UG degree in Electrical Engineering from Anna University, Chennai in 2008 and M.E. degree in Power Systems Engineering from Anna University, Tirunelveli, Tamil Nadu, India, in 2011. Since July 2011, he has been working as an Assistant Professor in the Department of Electrical \& Electronics Engineering, Kalasalingam University, Krishnankoil, Virudhunagar District, Tamil Nadu and India. He has attended several international conferences and he has been actively involving himself in research since 2013. Three of his research papers have been published in international journals and a research paper has been published in national journal. His current research interests include generation expansion planning, energy planning, power system optimization and power system control. He has actively participated in various faculty development programs, symposiums, orientation programs, workshops and national seminars. He has received Teaching Competency Award in the year 2015 and Research Competency Award in the year 2015 \& 2017. He is a Life member of ISTE and Member of IE(I).

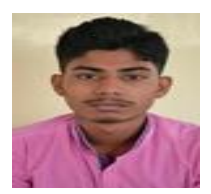

M. Nitish, UG Student, pursuing B.Tech degree in the field of Electrical and Electronics Engineering, Kalasalingam Academy of Research and Education, Anand Nagar, Krishnannkoil. 


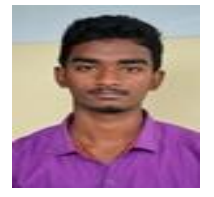

Yashwant Kumar. S, UG Student, pursuing B.Tech degree in the field of Electrical and Electronics Engineering, Kalasalingam Academy of Research and Education, Anand Nagar, Krishnannkoil.

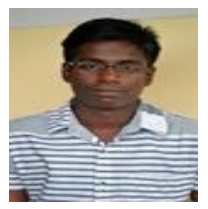

Edwin Deva Asirvatham. D, UG Student, pursuing B.Tech degree in the field of Electrical and Electronics Engineering, Kalasalingam Academy of Research and Education, Anand Nagar, Krishnannkoil.

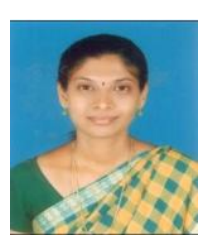

J.Booma received the B.E., Degree from Madurai Kamaraj University, Madurai, M.E., and Ph.D from Anna University, Chennai, She is presently working as Assistant Professor in the Department of Electrical and Electronics Engineering, PSNA College of Engineering and Technology, Dindigul, India. She has presented papers in more than 30 National and International conferences. She has published 10 papers in National and International Journals. Her field of interest includes Renewable Energy, Power system planning and Control Systems. She is a Life member of ISTE. 